\title{
Cochlearia and the Brassica Family: Carrying a Cross
}

\author{
Alex Leupen ${ }^{1}$ \\ 1 The Netherlands \\ Homœopathic Links 2017;30(1):57-58.
}

\begin{abstract}
Address for correspondence Dr. Alex Leupen, MD, Homeopatisch Artsencentrum Utrecht, Koningsweg 234, 3582 GM Utrecht, The Netherlands (e-mail: a.leupen@planet.nl).
\end{abstract}

\author{
Summary \\ Keywords \\ - Cross-bearing \\ - Bitter \\ - Flatulence \\ - Irritable bowel \\ syndrome \\ - Wrinkles
}

Alex Leupen works in the Homeopathic Doctors Centre in Utrecht, The Netherlands, since 1990. Eight colleagues work in this centre, including Jan Scholten. Alex is an experienced teacher on the underlying systems in the plant families and the periodic table of the elements pertaining to homeopathic practice. In this article, he shares clinical tips.

\section{Introduction}

Two important tools in my practice as a homeopathic doctor are the Periodic System, with the series and stages, and the Plant Theory, both of which have sprung from the brain of my colleague Jan Scholten, with whom I have been working closely for the past 26 years. Our offices are next to each other and I walk into his office a few times per day.

In the Plant Theory, every plant family is described in terms of its themes and issues. I shall use the Brassicaceae family as an example, illustrated by the remedy Cochlearia (-Fig. 1)

The Brassicaceae include all the cabbage sorts. The old name for this family is the Cruciferae, the cross flowers. In this plant family, we find homeopathic remedies such as Cochlearia officinalis, Thlaspi bursa pastoris, Sinapis nigra, Brassica napus, Raphanus.

They are often used in the treatment of irritable bowel syndrome: alternation of constipation and diarrhoea, with much flatulence.

According to Jan Scholten, this plant family is often useful for women who are the principal care-giver of their chronically ill partner, for instance someone with Parkinson's disease or Alzheimer's disease. They barely manage to find time for themselves or to have a life of their own, with their own social contacts, and finally they can become bitter. One could say that they feel they are carrying a cross; life is hard and difficult to digest. They feel as though they are caught in a trap. In Cochlearia, this manifests physically in the complaint: pain in the abdomen, extending through the flanks to the back.

The word 'bitter' suits the Brassicaceae; these vegetables are often sharp or bitter tasting: mustard, white cabbage, Brussels sprouts, radishes, horse radish. Those people who need these remedies are bitter themselves, feeling that life is a disappointment for them. Typical is their much wrinkled face.

\section{An Example from My Practice}

The patient came for the first consultation in November 1997 , a 29-year-old woman with abdominal cramps. She has a congenital muscular disease, but she does not have many symptoms yet. Her father, who has the same disease, is confined to a wheel chair. She lives together with her parents and takes care of them, looking after the whole household. Her mother has diabetes and bone cancer.

She has been having abdominal cramps since 4 years, and she also suffers from scoliosis. She has the urge to go to the toilet up to 25 times per morning; sometimes her stools are hard, sometimes loose. She has severe cramps which extend to her back. She sometimes walks bending over from the pain. Her belly feels tense, as though she has a tight band around it, worse from tight clothing. She has to loosen her belt. She is intolerant to cauliflower, onions, ground meat, spicy food, Chinese food, pickles and carbonated drinks. She does not have flatulence or eructations.
(C) 2017 Thieme Medical and Scientific Publishers Private Ltd.
DOI http://dx.doi.org/ 10.1055/s-0037-1598180. ISSN 1019-2050. 


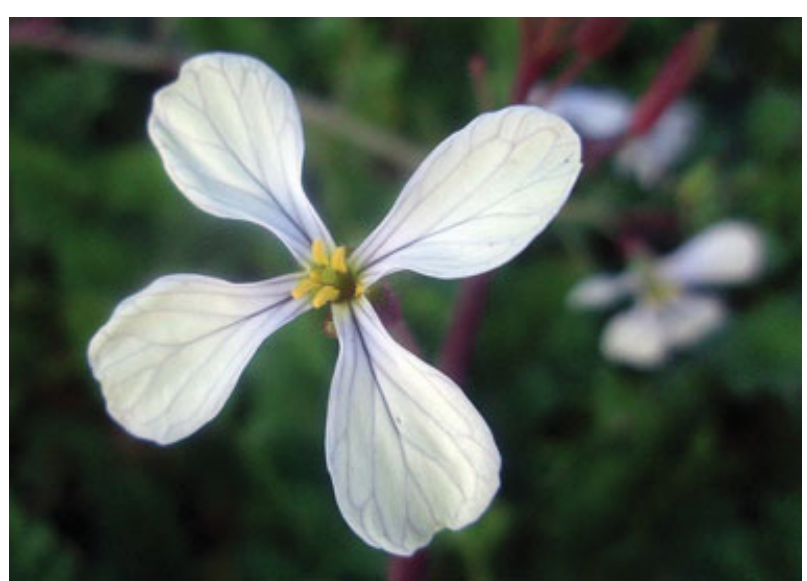

Fig. 1 Eruca vesicaria with cruciate tetramerous flowers typical of Cruciferae.

She is very dissatisfied with her family doctor and her specialist.

\section{Generals}

Temperature: She is chilly, with cold hands. She does not sweat much. She is worse before storms or rain.

Desires: Soup, warm food, cooked pears, vegetables, sweets.

Aversions: Rhubarb, pea soup.

Intolerances: Cauliflower, onions, ground meat, spicy food, Chinese food, pickles and carbonated drinks.

Thirst: Variable.

Stools: Variable.

Menses: She used oral anti-contraceptives due to irregular cycles. Before using the pill, she often had months with no menstruation, and then months with profuse bleeding, with clots and anaemia.

Sleep: She sleeps well, falls asleep quickly and sleeps through the night. Abdominal pain is worse while lying on her side, better from lying on her back. No night sweats. Dreams: She often dreams about her dog. The dog had swallowed something sharp and needed to have its mouth cleaned every day, otherwise it would suffocate.

Dream: Coming too late for the meeting about muscular illness.

Dream: A girlfriend would come and pick her up from the train station, but she does not come. She panics.

\section{Personality}

She does not want to be dependent on the help of anyone. 'I don't want to ask for help, I don't want to have to say thank you'.

Angry if she is not understood.

She cares for her ill parents. She does not have a boyfriend. Since 5 years she has a dog that is 'everything' for her.

Impatient, for instance if her father is in her way. She cannot stand to be blocked. Her brother has broken the contact with their parents. He would like to remain in contact with her, but she refuses this.

\section{Observation}

Ptosis. Emotionless face. Mild articulation difficulties. She often complains about her father, the doctors, her employer. Her general attitude is complaining.

\section{Analysis}

She is the principal care-giver of her chronically ill parents. She is bitter and complains a lot. She has hardly any life of her own. These are the issues of the Brassicaceae (Cruciferae). Abdominal pain extending to the back is a keynote for Cochlearia.

\section{Follow-up}

After one dose of Cochlearia, the pain disappeared completely within 1 month. After that she has not needed another dose, a minor miracle. Follow up after 19 years.

\section{Materia Medica of Boericke: Cochlearia armoracia}

[In the Materia Medica, Cochlearia officinalis is written as Cochlearia armoracia: unfortunately this name is incorrect. $\mathrm{AL}]^{1}$

Frontal bone and sinus, antrum and salivary glands are specifically affected by this drug. Bloated sensation. Raises vital forces. Used as a gargle in scorbutic gums and sore throat. Hoarseness and in relaxed conditions of the fauces. Internally in gonorrhoea. Useful as a condiment in enfeebled states of the stomach. An infusion of the root in cider, for dropsy, causes copious diuresis. Locally cures dandruff.

Head-Thinking is difficult. Anxiety, driven to despair by pain. Pressing, boring pain as if frontal bone would fall out. Violent headache with vomiting. Impaired hearing.

Eyes-Sore and scrofulous; traumatic inflammation of eyes, blearedness and cataract. Copious running from eyes.

Stomach-Pain toward back; worse, pressure on dorsal vertebrae. Belching and cramps. Colic with backache. Violent cramp from stomach through both sides around to back. Griping around navel.

Back-Pain in back as from incarcerated flatulence from abdomen through to back and down into sacrum.

Respiratory-Dry, hacking, laryngeal cough, also postinfluenzal cough, dry or loose, worse lying down. Chest painful to touch. Coryza, with hoarseness. Mucous asthma. Oedema of lungs. Throat feels rough and hoarse.

Urinary-Burning and cutting at glans penis before, during and after urination. Frequent urination.

Modalities-Worse evening and at night.

Relationship-Compare: Cannab, Sinapis, Caps.

With thanks to Deborah Collins for the translation.

\section{Reference}

1 Boericke W. Pocket Manual of Homœopathic Materia Medica. San Francisco: Boericke \& Runyon; 1927 (reprinted B. Jain Publishers, New Delhi 1988) 